\title{
Effective Use of Language by Managers in Diverse Workforce
}

\author{
Babita Mukherjee (Corresponding Author) \\ Lecturer, Department of General Sciences, College for Women, Prince Sultan University \\ King Abdullah Bin A. Aziz Road, Riyadh - 11586, Saudi Arabia \\ E-mail: bmukherjee@psu.edu.sa \\ Arooj Yaswi \\ Lecturer, Department of General Sciences, College for Women, Prince Sultan University \\ King Abdullah Bin A. Aziz Road, Riyadh - 11586, Saudi Arabia \\ E-mail: ayaswi@psu.edu.sa
}

\begin{abstract}
Ashavaree Das
Assistant Professor, Department of Applied Media, Higher College of Technology, United Arab Emirates

E-mail: Adas1@hct.ac.ae
\end{abstract}

Received: February 10, 2018 Accepted: March 28, 2018 Published: March 30, 2018

doi: 10.5296/jsss.v5i2.12914 URL: http://doi.org/10.5296/jsss.v5i2.12914

\begin{abstract}
Saudi Arabia has witnessed a high percentage of immigration in the past few decades as the influx of workers from different parts of the world has significantly increased during this time. This movement has caused an interaction between people having diverse languages, customs, and cultural backgrounds. Diversity has in turn led to a number of benefits, including enhanced employee creativity and competence. Due to the nature of the Saudi Arabian workplace; which is dominated by a foreign workforce, communication at workplace holds prime importance. A questionnaire was administered to 127 branch managers. This study
\end{abstract}


aimed at demonstrating the effects of communication; particularly language used by the managers at the workplace, on organizational effectiveness and how it is used to leverage the existing diversity and set a vibrant workplace environment.

Keywords: Language, Managers, Workforce Diversity, Organizational Effectiveness, Communication

\section{Introduction}

Managing workplace diversity has become a significant apprehension and an unavoidable factor in almost all the organizations in today's world. Workplace diversity management is prepared to recruit, reward and promote a heterogeneous coalesce of employees for the methodical and planned commitment by the organization (Bagshaw, 2004). The structure of the organizations and the movement for employment from and to various organizations has made the association within organizations very heterogeneous. With the boom of the internet age, and with cross-migrations from one country to another, organizations have now become more diverse; hosting people from an assortment of cultures, with more than often differing languages, norms, and rules and regulations. More specifically, organizations today accommodate diverse work ethics, work cultures, and therefore, varying degree of workplace conflicts. Thus, this opportunity has encouraged the organizations to create the most out of the conflicts from a diverse workforce instead of losing the capability which may help the organizations to be more capable and influential (Bryan, 1999).

While the dynamics within an organization are continually changing, the organizational objectives however remain the same. It has now become an increasingly difficult task to maneuver individual interests to converge into the combined organizational objectives. In such scenarios, the role of the manager, therefore, comes to the limelight. It becomes the responsibility of the manager to ensure that the organizational objectives are met, and at the same time; that, the individual needs of the employees from diverse backgrounds are also taken into cognizance. However, among the important factors that affect the managers to manage the workplace diversity to reach organizational effectiveness is the way in which language is used for communication.

Diversity is considered as a fundamental part of business and subsequently is being incorporated in many organizations, as it helps in expanding efficiency and enhancing the quality of management (Meena \& Vanka, 2013). Managing diversity depends on the diversity approach, which underlines that people are an important resource needed to attain and succeed in attaining a competitive advantage that will benefit the organisation (Mukherjee, Gambhir, \& Yaswi, 2015); and effective use or misuse of language can make or break workplace communication. Thus, effective communication based on effective use of language is the backbone of progress in any organization, since the ultimate goal of any organization is to efficiently reach its objectives using appropriate language. However, managing diversity in organizations is dependent upon the implementation of the dimensions to which employees are willing to communicate and hold trust.

A significant request on the impact of demographic diversity on organizational performance has provided strong support to strengthen well-managed diverse workplace. Workplace today is getting more and more heterogenous in terms of age, gender, race, ethinicity, language, 
religion etc. While organizations benefit from this diversity, they also face a solid challenge in safeguarding themselves from complexities, communication problems, and conflicts that arise from the same diversity. Kundu (2004) notes that companies that want to grow rely on building a culture that recognizes and celebrates diversity, most often enjoying support from top management .

In order for organizations to remain competitive, it is essential for businesses to hold on to the differences and at the same time search out every single operational strategy that will attract the talent required within the organization. The blend of groups in the workplace has created a challenge for managers, who must dispense in a scenario of contending values and priorities of the different groups. There is a great debate over whether experience, language know-how or a college degree is more important in doing the activities in the job. Some indicate that experience builds up for the deficiency of a degree; others suppose a degree provides something that experience cannot and furthermore proficiency at different languages provides an edge in performing the task. So it is important to look into how diversity management can improve the corporate refinement of an arrangement and establish the organization in such a way to gain a competitive advantage. Therefore, this paper attempts to analyze the statements affecting workplace diversity management in context of language used by the managers to achieve the organization's strength and thus studies the following research question: What is the perceived language effectiveness of managers in the diverse workforce.

\section{Literature Review}

Diversity in the workforce, according to Sadri and Tran (2002), has become a demographic reality all around the globe. It is presently a theory as opposed to an exemption (Angouri, 2013). It has become incumbent to manage this diversity as opposed to just acknowledge it. Promoting integration and equality stay at the crux of the issue. This can be achieved by managing personal growth and mentoring. However, in managing a global workforce, there is often a communication gap between the management and the employees. Managers now need to communicate across languages and cultures (Dowling \& Welch, 2004). Being able to communicate in a diverse workplace is essential in making a manager successful (Bonache \& Brewster, 2001).

Smoliar (2003) argues that more emphasis should be paid to the management of people as opposed to the dissemination of knowledge. The study suggests that limiting interaction among the members of an organization is very restrictive. Instead of just focusing on how information can be exchanged, the focus should be on leveraging social interactions so that the organizational objectives are met. Since organizations now are diverse, the use of communication and, more specifically language becomes an important factor in organizational growth.

An emphasis has been laid on the need for training programs where organizations host employees from various cultural backgrounds. A guideline for training programs has been provided by Nixon and Dawson (2002) based on their study of three major co-cultures in the United States. They propose that for communication to be effective, it is essential to consider the problems that might arise while communicating between the various co-cultures. Although heterogeneity can have both positive and negative effects, it is more difficult for such groups to communicate and develop work norms (Behfar \& Brett, 2006). Hence 
communicating effectively with employees becomes an added task for managers.

Dhir (2005) studied the concept of evolution of the knowledge economy, globalization and diversity in the workplace. The study suggested that managing language is a corporate asset; language leading to the intellectual and organizational capital. Language helps define the organization's culture and strategic environment. Employees of many Multinational Companies and other big organizations have not only diversity in cultures but also language (Fredriksson, Barner-Rasmussen, \& Piekkari, 2006). Language is not just a process which leads to understanding but also an object of the action (Taylor, 2006). It is not possible to have a unified use of communication within organizations that are multilingual. Thus, ignoring the role of language in diverse organizations may hinder the organizational growth and may also lead to loss of resources (Lauring, 2007). It is essential to take into consideration the outcome of the nomenclature employed in such systems. Understanding how language is used within organizations can also help understand the social strategies of inclusion and exclusion.

De Groot (2012) provided insights into the efficient use of language in diverse companies. According to the research, although English is the prima lingua, it is not necessarily effective in all setups. Language background plays an important role in understanding and synthesizing information. The study proposed the formation of corporate language policy which should be tailor-made to fit the organizational objectives of individual organizations. Another study by Tange (2009) proposed the need for liaison between language policy makers and organizational language brokers. In most of the corporations, English is the prime language used, alongside others. The official language policy explores how top-down management and bottom-up perspectives correlate (Kingsley, 2013)

Language proficiency, race, and educational levels have an impact on how the employee identifies himself with the organization. Holtzhausen and Fourie (2008), in a study conducted in a mining company in South Africa, found that although race and educational level did not create much difference in forming a corporate identity; the employee's English proficiency made a marked difference. This implies that managers should be aware of what language they choose when communication leads to information dissemination.

While analyzing the role of the manager in creating effective communication, building trust is an important factor (Dunn, Grannan, Raisinghani, \& Stalling, 2015). In a study using Ghanaian organizations, Abugre (2012) analyzed how managerial interactions with employees affect work output. The study found that those regular interactions had a direct positive effect on the work output given by the employees. It is, hence, safe to say that to induce a pronounced difference in performance, and the achievement of organizational goals, a lucid climate of social interactions is of prime importance.It has often been cited that being smart is more effective for higher positions than being social. Fragale (2005) points out that verbal and nonverbal behaviours mirror the member position in a task group. Angouri (2013) proposes that the language used becomes flexible where 'whatever works' is taken as the attitude.

Sharma and Kamalanabhan (2012) examined the internal corporate communication process and its outcomes in the context of the Indian Petroleum Public sector. They found a relationship between dimensions of communication and internal branding outcomes. They 
also found that these practices led to communication satisfaction, which in turn affected loyalty and commitment among the employees. In certain studies, about places where there were multiple information and communication channels used for sharing knowledge, it was found that participants relied on face to face interactions, and email sharing (Snyder \& Lee-Partridge, 2013). The language used thus becomes an important factor in the understanding of information and its dissemination to various groups (Cooren, 2006).

Conflict is an inevitable element of diverse workplaces. Crisis management in terms of such workplaces has been largely unexplored. Frandsen and Johansen (2011) indicated that it is significant to deliver a detailed study of the kinship between an organization and its internal stakeholders. For reaching the organizational objectives without the pitfall of conflicts, it is imperative to apply a staged approach. This enables the mitigation of crisis from initial communication to post-crisis stage.

Baccarani and Bonfanti (2015) explore how effective public speaking affects corporate communication. It is argued that effective public speaking; where the speaker is speaking to the audience rather than them being as spectators' leads to professional growth and motivated human resources. The use of language is of utmost importance for any kind of public speaking. Therefore, how language is used by managers will directly affect whether organizational goals are met or not.

A batch of surveys has been conducted on how managers maintain their impressions through computer-mediated communication. There is a difference in how the managers start and close their emails based on whether they are using their smartphone or their office computer (Caron, Hwang, Brummans \& Caronia, 2013). The language usage shifts from being informal to formal and vice versa. This transition also has an effect on the relationship between managers and employees, and how organizational objectives are dealt with and handled.

Organizational communication scales need to be readdressed to make them applicable to organizations that are diverse. Most of the scales fit the Western model of organizational settings, which might not always work for diverse organizations, especially the ones in the Middle East. One such research was conducted by Abu Bakar and Mustaffa (2013), wherein they tried to see if the Western model was applicable to the more collectivist culture based organizations. The paper found that within the Malaysian context, group bond and respect were the paramount forces. From this research, it is safe to say that the communication style used by managers and employees would follow the same premise. Hence, the language used by managers ultimately has an effect on how goals are communicated.

According to the Australian model for managing cultural diversity (Syed \& Kramer, 2010), an integrated approach of management; working at multiple levels, is necessary for smooth functioning of a diverse workplace. It is incumbent on managers to demonstrate their willingness to make such programs successful. Roberson, Bell, and Porter (2008) propose a team input-process-output model that takes into account language and its effect on teams. The proposal is based on the relationship between language and diversity.

Engaged employees have always created successful organizations. In order to have employees who are engaged, it is necessary to check the communication channels and communication attributes. Men and Hung-Baesecke (2015) conducted a survey in China, the 
results pointed out that effective interaction within the organizations leads to better employee engagement. The more the employees are engaged, the easier it is to reach the organizational objectives. There is now a widespread use of mediated and digital mediums of communication. However the importance of direct communication should not be ignored (Lipiainen, Karjaluoto, \& Nevalainen, 2014).

A body of research points toward the role played by language in managing diversity. There is a clear indication that the benefits of organizational diversity can be accrued, given the establishment values and how it handles diversity. However, little consideration has been given to how such diversity promotes organizational effectiveness and goal attainment.This study will add to the literature by showing how diversity in organizations influences organizational effectiveness specifically relating to language use in the local context.

\section{Research Design}

The study was completed using the survey method, wherein a sample of 127 branch managers from 185 companies in Riyadh were selected randomly and the response rate was $68.6 \%$. The questionnaire consists of two sections. Section 1 consisted of 6 items measuring the personal profile and demographic characteristics of respondents and section 2 consisted of 5 items measuring language used by the managers in their workplace using a 6-point Likert scale. The data was analyzed using SPSS. The information was analyzed through descriptive frequencies. The reliability test of the Likert items was conducted, and the value was 0.780 which was acceptable according to Nunnally (1978).

\section{Findings and Discussion}

\subsection{Socio-Demographic Profile}

Socio-demographic data of the respondents, which comprised of nationality, age, gender, marital status, education level, length in service were calculated using descriptive statistics. Based on Table1, there were $77(60.6 \%)$ of Saudi nationality, 19 (15\%) of Egyptian nationality, $12(9.4 \%)$ of Pakistani nationality, and 7 (5.5\%) of Indian nationality. In addition to this, approximately $12(9.4 \%)$ of the sample were from the Levant (Jordan, Syria and Lebanon). There were $124(97.6 \%)$ male respondents and $3(2.4 \%)$ female respondents. The respondents were arranged into five age categories to be specific; 29 and below years of age, between 30-34 years of age, 35-39 years of age, 40-49 years of age or more 50 years of age. Most of the respondents were sorted between 35-39 years of age (30.7\%). Most of the respondents $103(81.1 \%)$ were married, and only $24(18.9 \%)$ respondents were single. 70 $(55.1 \%)$ respondents were college graduates, and 44 (34.6\%) of the respondents had 5-9 years of length of employment. 
Table 1. Socio - demographic profile of respondents

\begin{tabular}{|c|c|c|}
\hline Respondent Profile & Frequency $(n=127)$ & Percentage \\
\hline Saudi & 77 & 60.6 \\
\hline Pakistani & 12 & 9.4 \\
\hline Egyptian & 19 & 15.0 \\
\hline Indian & 7 & 5.5 \\
\hline Others & 12 & 9.4 \\
\hline \multicolumn{3}{|l|}{ Age Group } \\
\hline Less than 29 & 16 & 12.6 \\
\hline $30-34$ & 30 & 23.6 \\
\hline $35-39$ & 39 & 30.7 \\
\hline $40-49$ & 29 & 22.8 \\
\hline 50 and Above & 13 & 10.2 \\
\hline \multicolumn{3}{|l|}{ Gender } \\
\hline Male & 124 & 97.6 \\
\hline Female & 3 & 2.4 \\
\hline \multicolumn{3}{|l|}{ Civil Status } \\
\hline Married & 103 & 81.1 \\
\hline Single & 24 & 18.9 \\
\hline \multicolumn{3}{|l|}{ Education Attainment } \\
\hline High School Graduate & 8 & 6.3 \\
\hline College Undergraduate & 5 & 3.9 \\
\hline College Graduate & 70 & 55.1 \\
\hline Master Degree & 38 & 29.9 \\
\hline Others & 6 & 4.7 \\
\hline \multicolumn{3}{|l|}{ Length in Service } \\
\hline Below 1 Year & 3 & 2.4 \\
\hline $1-4$ & 17 & 13.4 \\
\hline $5-9$ & 44 & 34.6 \\
\hline $10-14$ & 24 & 18.9 \\
\hline $15-19$ & 20 & 15.7 \\
\hline 20 and Above & 19 & 15.0 \\
\hline
\end{tabular}




\subsection{Assessment of Reliability}

2018, Vol. 5, No. 2

Table 2 shows the reliability value as 0.780 . According to Nunnally (1978), the reliability of 0.70 or higher is acceptable. The questionnaire was administered for the first time face to face to make the respondent understand the purpose of the study and then were given to send the responses later by e-mail or by mail.

Table 2. Reliability test of 127 respondents

\begin{tabular}{ll}
\hline Cronbach's Alpha & No of Items \\
\hline 0.780 & 5 \\
\hline
\end{tabular}

\subsection{Mean Ranking}

Table 3 shows the mean score of language used statements which was in the range 4.37 to 4.87 out of 5.00 and thus managers believe that language demonstrates the competences in the multicultural environment with higher mean value whereas use of appropriate tone or pitch is having the least mean value.

The mean score of language used which was 4.64 out of 5.00 and thus signifying that managers in Riyadh are having a higher preference towards using foreign language with proper tone and pitch in the working environment.

Table 3. Mean score of language

\begin{tabular}{lrl}
\hline Statements & Mean & $\begin{array}{c}\text { Standard } \\
\text { Deviation }\end{array}$ \\
\hline Language Score* & $\mathbf{4 . 6 4}$ & $\mathbf{0 . 8 6 7}$ \\
\hline $\begin{array}{l}\text { Possesses basic knowledge about common languages used in the } \\
\text { organisation }\end{array}$ & 4.43 & 1.400 \\
Uses language understood by the majority of the workforce & 4.83 & 1.187 \\
Uses English as a foreign language & 4.73 & 1.123 \\
Uses appropriate paralinguistic cues & 4.37 & 1.133 \\
Demonstrates competence in multicultural interaction & 4.87 & 1.076 \\
\hline
\end{tabular}

$\mathrm{n}=127 ;$ * Measure by 5 measured items.

\subsection{Language and Communication Concerns}

Language has been considered an important dimension of cultural difference. When asked if the manager had a basic knowledge of common languages used in the organization, there was a strong indication that a language barrier was not a concern to survey respondents, with $75.6 \%$ respondents agreeing that managers effectively used common language to communicate with others. However, around $14.2 \%$ of respondents did not believe a common language was being used to facilitate communication by the managers at the workplace. 


\section{Macrothink Institute ${ }^{\mathrm{TM}}$}

Respondents who worked in the companies in Riyadh said they used English frequently as a common language and Arabic also being used to serve the purpose (Figure 1). In contrast to the responses to the question regarding the understanding of the language used by the majority of the workforce in order to facilitate communication, a significant number of respondents $(87.4 \%)$ reported that it was easy to communicate with coworkers (Figure 2). Over $87.5 \%$ of respondents agreed that managers can speak a foreign language as (English Language) the employees with diverse backgrounds are better able to communicate with coworkers from diverse backgrounds (Figure 3). When asked whether managers can change his/her accent or tone when a multicultural interaction requires or not to communicate with people from diverse backgrounds, $81.1 \%$ of the coworkers had agreed upon (Figure 4), and $89.7 \%$ of the employees agreed that the managers respect the speech style of the employees within the organisation (Figure 5).

Table 4. Effect of language and communication in diverse workforce

\begin{tabular}{lllllll}
\hline & $\begin{array}{l}\text { Very } \\
\text { Ineffective }\end{array}$ & Ineffective & $\begin{array}{l}\text { Less } \\
\text { Effective }\end{array}$ & $\begin{array}{l}\text { Moderately } \\
\text { Effective }\end{array}$ & Effective & $\begin{array}{l}\text { Very } \\
\text { Effective }\end{array}$ \\
\hline $\begin{array}{l}\text { Possesses basic knowledge } \\
\text { about common languages } \\
\text { used in the organisation }\end{array}$ & $3(2.4 \%)$ & $15(11.8 \%)$ & 13 & $22(17.3 \%)$ & 42 & 32 \\
$(10.2 \%)$ & & $(33.1 \%)$ & $(25.2 \%)$ \\
$\begin{array}{l}\text { Uses language understood } \\
\text { by the majority of the } \\
\text { workforce }\end{array}$ & $4(3.1 \%)$ & $1(0.8 \%)$ & $11(8.7 \%)$ & $22(17.3 \%)$ & 47 & 42 \\
$\begin{array}{l}\text { Uses English as a foreign } \\
\text { language }\end{array}$ & $2(1.6 \%)$ & $4(3.1 \%)$ & $10(7.8 \%)$ & $27(21.3 \%)$ & $51(40.2 \%)$ & $33(26.0 \%)$ \\
$\begin{array}{l}\text { Uses appropriate } \\
\text { paralinguistic cues (tone, } \\
\text { pitch) }\end{array}$ & $1(0.8 \%)$ & $8(6.3 \%)$ & $15(11.8 \%)$ & $43(33.9 \%)$ & $39(30.7 \%)$ & $21(16.5 \%)$ \\
$\begin{array}{l}\text { Demonstrates competence } \\
\text { in multicultural interaction }\end{array}$ & $2(1.6 \%)$ & $2(1.6 \%)$ & $9(7.1 \%)$ & $23(18.1 \%)$ & $52(40.9 \%)$ & $39(30.7 \%)$ \\
\hline
\end{tabular}




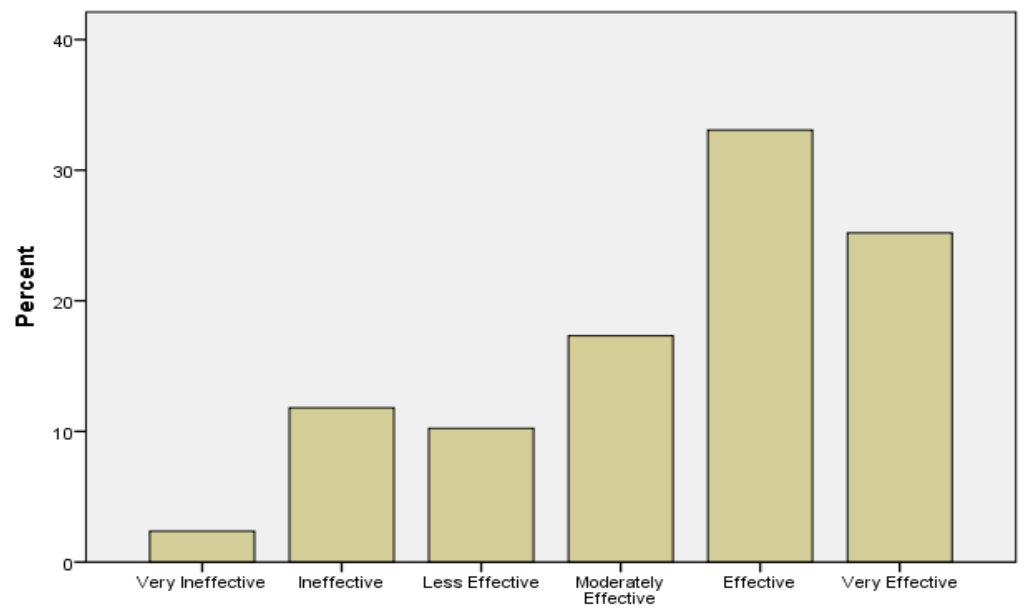

Figure 1. Possesses basic knowledge about common languages used in the organization

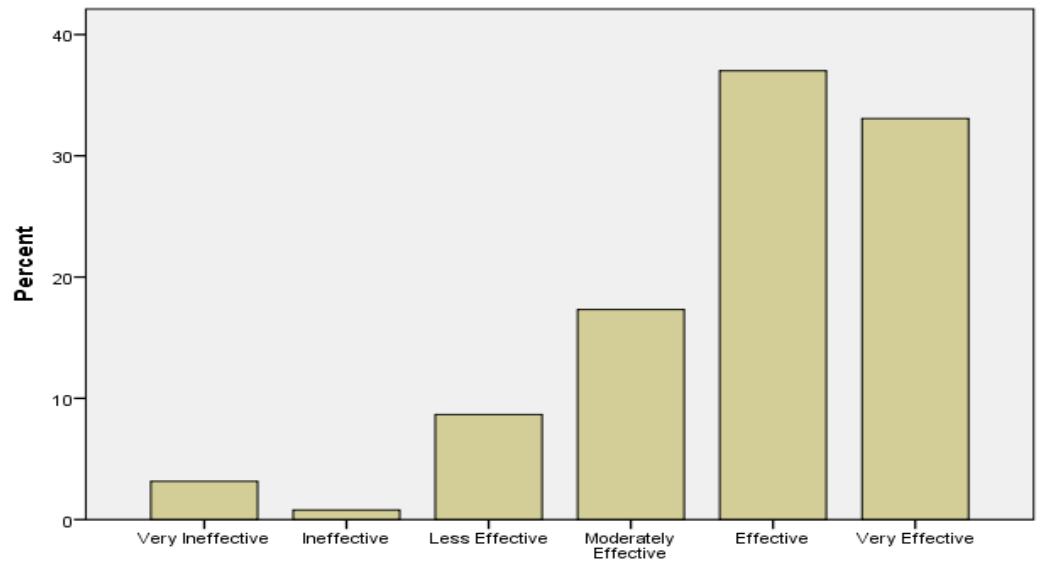

Figure 2. Uses language understood by the majority of the workforce



Figure 3. Uses English as a foreign language 


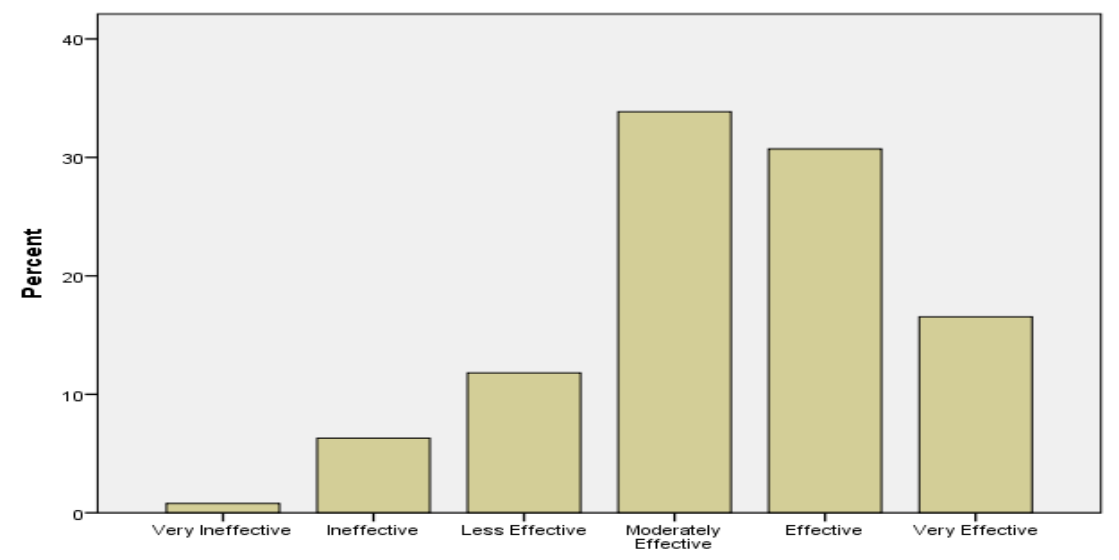

Figure 4. Uses appropriate paralinguistic cues

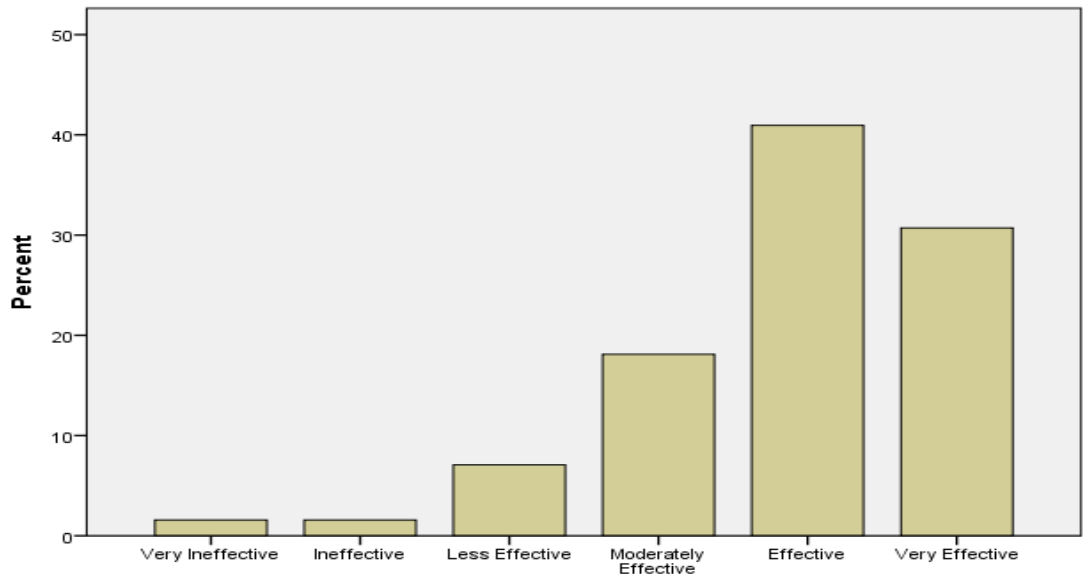

Figure 5. Demonstrates competence in multicultural interaction

\subsection{Findings for t-test}

The results show that there is significant difference in terms of language used in the organizations in Riyadh. All the statements of language used have a p-value less than 0.05 . Table 5 provides the details of mean difference for each one of the variable. The highest mean difference between the variables is shown by the variables demonstrates competence in multicultural interaction (4.874) followed by "uses language understood by the majority of the workforce (4.835). 
Table 5. Shows the t-test results of the Language Used

\begin{tabular}{|c|c|c|c|c|c|c|}
\hline & \multicolumn{6}{|c|}{ Test Value $=0$} \\
\hline & \multirow[t]{2}{*}{$\mathrm{T}$} & \multirow[t]{2}{*}{$\mathrm{df}$} & \multirow[t]{2}{*}{$\begin{array}{l}\text { Sig. } \\
\text { (2-tailed) }\end{array}$} & \multirow[t]{2}{*}{$\begin{array}{l}\text { Mean } \\
\text { Difference }\end{array}$} & \multicolumn{2}{|c|}{$\begin{array}{l}95 \% \text { Confidence } \\
\text { Interval of the } \\
\text { Difference }\end{array}$} \\
\hline & & & & & Lower & Upper \\
\hline $\begin{array}{l}\text { Possesses basic knowledge } \\
\text { about common languages used } \\
\text { in the organization }\end{array}$ & 35.615 & 126 & 0.000 & 4.425 & 4.18 & 4.67 \\
\hline $\begin{array}{l}\text { Uses language understood } \\
\text { by the majority of the workforce }\end{array}$ & 45.901 & 126 & 0.000 & 4.835 & 4.63 & 5.04 \\
\hline Uses English as a foreign language & 47.490 & 126 & 0.000 & 4.732 & 4.54 & 4.93 \\
\hline $\begin{array}{l}\text { Uses appropriate paralinguistic } \\
\text { cues }\end{array}$ & 43.486 & 126 & 0.000 & 4.370 & 4.17 & 4.57 \\
\hline $\begin{array}{l}\text { Demonstrates competence } \\
\text { in multicultural interaction }\end{array}$ & 51.029 & 126 & 0.000 & 4.874 & 4.68 & 5.06 \\
\hline
\end{tabular}

\section{Conclusion and Discussion}

This study set out to investigate the language and communication choices of managers in Saudi Arabian organizations in Riyadh. Overall the results indicated that most respondents perceived the communication styles used as favorable, indicate moderately effective to very effective responses on six-point Likert scale questions. Inspite of being descriptive in nature, this study has been able to demonstrate the language strategy chosen by managers in organizations.

It appears that most of the respondents were particularly positive about possessing basic knowledge about common languages used in the organization. Additionally, most agreed that the language used was understood by the majority of the workforce in order to facilitate communication. A majority $(87.5 \%)$ were able to speak English. Although the study confirmed that $75.6 \%$ of the managers had basic knowledge about the common languages in the organization, a small but significant $14 \%$ disagreed on this. This opens up opportunities within the organizations to assess communication needs of the employees.

Effective communications are vital to the working of a company, and in this case, language becomes a critical factor. As a whole, positive ratings towards language use were found among employees. Knowledge of English language allows for better communication with coworkers from diverse backgrounds. Furthermore, as English is increasingly chosen as a common corporate language by other multinational corporations, business communication between different organizations would become much easier.

Managers were also rated on paralinguistic competencies aspects of language that focus on how something is said (Trenholm, 2014). These aspects consist of vocal quality, vocal 
segregates, and vocalizations. In a diverse world, it becomes essential for managers to comprehend and grasp the fundamentals of a multicultural interaction. Just like verbal competence, this aspect focuses on the nonverbal competence of managers and refers to the ability to encode and decode messages skillfully. A majority of the employees positively rated managers for paralinguistic ability. The paralinguistic ability has been categorized as a core communication competency by most Human Resource (HR) managers (English, Manton, \& Walker, 2007). Finally, a majority (81.1\%) agreed the speech style of employees was respected.

It is important to note some limitations of this study. Data participants were based on a random sample. It is also possible that participants may have forwarded biased responses based on personal opinions, personality, and social desirability. Nevertheless, this study substantiates previous research findings on language use and initiates inquiry into one of the most vital aspects of intra-organizational phenomena communication. This research encourages the possibility of conducting language (verbal and nonverbal) skill audits in organizations, which in turn can create opportunities for effective training programs for managers as well as employees.

Future research should focus on perceived effectiveness of languages while managing workplace diversity. In addition to this, specific communication competencies need to be studied as well. These competencies include but are not limited to practical aspects of communication (oral and written), socio-interpersonal aspects, group communication, and evaluative aspects (development of competencies of communication evaluation).

\section{References}

Abu Bakar, H., \& Mustaffa, C. S (2013). Organizational communication in Malaysia organizations: Incorporating cultural values in communication scale. Corporate Communications: An International Journal, 18(1), 87-109. https://doi.org/10.1108/13563281311294146

Abugre, J. B. (2012). How managerial interactions affect employees' work output in Ghanaian organizations. African Journal of Economic and Management Studies, 3(2), 204-226. https://doi.org/10.1108/20400701211265009

Angouri, J. (2013). The multilingual reality of the multinational workplace: language policy and language use. Journal of Multilingual and Multicultural Development, 34(6), 564-581. https://doi.org/10.1080/01434632.2013.807273

Baccarani, C., \& Bonfanti, A. (2015). Effective public speaking: a conceptual framework in the corporate-communication field. Corporate Communications: An International Journal, 20(3), 375-390. https://doi.org/10.1108/CCIJ-04-2014-0025

Bagshaw, M. (2004). Is diversity divisive? A positive training approach. Industrial \& Commercial Training, 36(4), 153-157. https://doi.org/10.1108/00197850410542383

Behfar, K., Kern, M., \& Brett, J. (2006). Managing challenges. In multicultural teams. In National culture and groups, 233-262. Emerald Group Publishing Limited.

Bonache, J., \& Brewster, C. (2001). Knowledge transfer and the management of expatriation. Thunderbird International Business Review, 43(1), 145-168. https://doi.org/10.1002/1520-6874(200101/02) 
Caron, A. H., Hwang, J. M., Brummans, B. H., \& Caronia, L. (2013). Business writing on the go: How executives manage impressions through e-mail communication in everyday work life. Corporate Communications: An International Journal, 18(1), 8-25. https://doi.org/10.1108/13563281311294100

Cooren, F. (2006). The organizational world as a plenum of agencies. Communication as organizing: Empirical and theoretical explorations in the dynamic of text and conversation, 81-100.

De Groot, E. B (2012). Personal preference or policy? Language choice in a European based international organization. Corporate Communications: An International Journal, 17(3), 255-271. https://doi.org/10.1108/13563281211253511

Dhir, K. S. (2005). The value of language: concept, perspectives, and policies. Corporate Communications: An International Journal, 10(4), 358-382. https://doi.org/10.1108/13563280510630151

Dowling, P. J., \& Welch, D. E. (2004). International Human Resource Management: Managing People in a Multinational Environment (4th ed.), Thomson Learning, London.

Dunn, S., Grannan, C., Raisinghani, M., \& Stalling, H. (2015, January). Communication Strategies for Successful Virtual Teams. In System Sciences (HICSS), 2015 48th Hawaii International Conference on (pp. 364-373). IEEE.

English, D. E., Manton, E. J., \& Walker, J. (2007). Human resource managers' perception of selected communication competencies. Education, 127(3), 410-419.

Fragale, A. R. (2005). To be Smart or to be Social? The Context-Dependent Effects of Communication Styles on Status Conferral in Task Groups, In Melissa C. Thomas-Hunt (Ed.), Status and Groups (Research on Managing Groups and Teams, Volume 7, pp. 93-119) Emerald Group Publishing Limited.

Frandsen, F., \& Johansen, W. (2011). The study of internal crisis communication: towards an integrative framework. Corporate Communications: An International Journal, 16(4), 347-361. https://doi.org/10.1108/13563281111186977

Fredriksson, R., Barner - Rasmussen, W., \& Piekkari, R. (2006). The multinational corporation as a multilingual organization: The notion of a common corporate language. Corporate Communications: An International Journal, 11(4), 406-423. https://doi.org/10.1108/13563280610713879

Holtzhausen, L., \& Fourie, L. (2008). Communicating to a diverse workforce: Employees' perceptions of symbolic corporate identity elements. Corporate Communications: An International Journal, 13(1), 80-94. https://doi.org/10.1108/13563280810848210

Kingsley, L (2013). Language choice in encounters in multilingual and transnational workspaces. Journal of Multilingual and Multicultural Development, 34(6), 533-548. https://doi.org/10.1080/01434632.2013.807271

Kundu, S. C. (2004). HR diversity: A study of employees' perceptions in the Indian context. Asian Pacific Management Review, 9(1), 39-59.

Lauring, J. (2007). Language and ethnicity in international management. Corporate Communications: An International Journal, 12(3), 25-266. 
https://doi.org/10.1108/13563280710776851

Lipiäinen, H. S. M., Karjaluoto, H. E., \& Nevalainen, M. (2014). Digital channels in the internal communication of a multinational corporation. Corporate Communications: An International Journal, 19(3), 275-286. https://doi.org/10.1108/CCIJ-07-2012-0050

Men, L. R., \& Hung-Baesecke, C. F. (2015). Engaging employees in China: The impact of communication channels, organizational transparency, and authenticity. Corporate Communications: An International Journal, 20(4), 448-467. https://doi.org/10.1108/CCIJ-11-2014-0079

Meena, K., \& Sita Vanka, J. (2013). Diversity Management and Human Resource Development-A Study of Indian Organizations. Pacific Business Review International, 5(7), 45-51.

Mukherjee, B., Gambhir, D., \& Yaswi, A. (2015). Socio-Demographic Characteristics of Managers and Employees Attitude Towards Managing the Workplace Diversity. Journal of Social Science Studies, 2(2).

Nixon, J. C., \& Dawson, G. A. (2002). Reason for cross - cultural communication training. Corporate Communications: An International Journal, 7(3), 184-191. https://doi.org/10.1108/13563280210436790

Nunnaly, J. (1978). Psychometric Theory (2nd ed.). New York: McGraw-Hill

Roberson, Q. M., Bell, B., \& Porter, S .C. (2008). The language of bias: A linguistic approach to understanding intergroup relations. In K. W. Phillips (Ed.), Research in Managing Groups and Teams: Diversity and Groups, 11, 267-294. Bingley, UK: Emerald

Sadri, G., \& Tran, H. (2002). Managing your diverse workforce through improved communication. Journal of Management Development, 21(3), 227-237. https://doi.org/10.1108/02621710210420291

Sharma, N., \& Kamalanabhan, T. J. (2012). Internal corporate communication and its impact on internal branding: Perception of Indian public sector employees. Corporate Communications: An International Journal, 17(3), 300-322. https://doi.org/10.1108/13563281211253548

Smoliar, S. W. (2003). Interaction management: The next (and necessary) step beyond knowledge management. Business Process Management Journal, 9(3), 337-353. https://doi.org/10.1108/14637150310477920

Snyder, J., \& Lee-Partridge, J. E. (2013). Understanding communication channel choices in team knowledge sharing. Corporate Communications: An International Journal, 18(4), 417-431. https://doi.org/10.1108/CCIJ-03-2012-0026

Syed, J., \& Kramar, R. (2010). What is the Australian model for managing cultural diversity? Personnel Review, 39(1), 96-115. https://doi.org/10.1108/00483481011007887

Tange, H. (2009). Language workers and the practice of language management. Corporate Communications. An International Journal, 14(2), 131-143. https://doi.org/10.1108/13563280910953825

Taylor, L. (2006). The changing landscape of English: Implications for language assessment. ELT Journal, 60(1), 51-60. 
Trenholm, S. (2014). Thinking through communication: An introduction to the study of human communication (7th ed.). Upper Saddle River, New Jersey. Pearson.

\section{Copyright Disclaimer}

Copyright for this article is retained by the author(s), with first publication rights granted to the journal.

This is an open-access article distributed under the terms and conditions of the Creative Commons Attribution license (http://creativecommons.org/licenses/by/3.0/). 